provide supervision of the same quality and quantity as the rich. But this is not something that can be easily remedied through a behaviourally oriented preventive program. It can do little good to harp on the need for closer supervision, when families are already overwhelmed with trying to survive. Instead, the emphasis must be on trying to make it easier for these parents to protect their children using other strategies. Whether these strategies are population based or targeted is the only issue; the fact that special efforts are needed cannot be denied.

But, to repeat, if we were to approach this problem as a challenge for primary prevention, the obvious solution is to diminish the proportion of poor children. Although some countries have gone much further in this direction than others, all should do so and not simply for the sake of preventing injuries. There are many other more persuasive reasons why any civilized country should want to reduce poverty, especially as it affects children.

Steps, such as those taken in parts of the Netherlands recently, to reduce unemployment and thus, poverty, through encouraging a four day work week, deserve wide consideration. Countries with a high proportion of poor children should re-examine the economic and political wisdom of following this example. The merits, or otherwise, of other economic approaches, including income redistribution and taxation policies, are beyond my ability to comment on wisely. But there can be no escape from the fact that until we find effective preventive strategies, targeted or otherwise, poor children will continue to have higher injury rates. The primary prevention solution is to make these families less poor and to have fewer of them.

It is at the secondary prevention level where the argument between targeted versus population strategies hits home. Assuming that poverty is going to be with us, which approach is most likely to benefit most or is less likely to prove harmful in reducing the toll of injuries or their immediate consequences?

As stated earlier, I long believed that Geoffrey Rose was right, but the arguments put forward in this issue are cause for further reflection. It would be important to know what others think about this critically important issue.

The best case scenario is to suggest that both population and high risk approaches could coexist. If it were not a choice between using limited resources for either one, it would be interesting to consider these alongside one another. So, for example, one could imagine a nationwide campaign to reduce speeds, which, if successful would benefit everyone, alongside more vigorous enforcement of reduced speed limits in poor areas. Similarly, if parenta年 accompaniment is the key to the safety of child pedestrianes under the age of 10 , and this is so difficult for poor parents te provide, society has an obligation to take other steps Programs to find others to accompany children on trips t $\bar{\phi}$ and from school may be one answer. Another is to ensure that traffic is less dangerous, either by slowing it or re= routing it.

I have a hunch that one reason why children in poor areas have higher injury rates is that enforcement of existing laws and regulations is less evident in those areas. For example if speed limits are not obeyed in low income neighbour hoods, or in poor countries, there is less time or energy of clout available to the poor to complain as effectively as the rich. This is, of course, a hypothesis, but it should be possible to prove, and if proven, would point to $\vec{a}$ generalizable solution.

Finally, at the level of tertiary prevention, there are certain to be disparities in the manner in which these post injury services are provided, if indeed, they are available a€ all. Despite not knowing much about what it is aboute tertiary care that has accounted for the remarkable decline in death rates, doubtlessly those living in more affluent areas are the main beneficiaries of this technology. Thip disparity can, and should, be remedied world wide. The World Health Organisation, a major player in low incomè countries with a growing commitment to injury prevention must move more forcefully to achieve this goal as well as those at the primary and secondary levels. The UN Development Program intends that the findings of this year's report be used by the world's rich nations to set the goal of eradicating world poverty within the next 15-20. years. Although this timetable is too leisurely for my liking it confirms that the objective is realistic.

1 Rose G. The strategy of preventive medicine. Oxford: Oxford University Press 1992.

\title{
A poignant example
}

Just before completing the preceding editorial, a 6 year old child was killed while skate-boarding in a Montreal suburb. In itself, this event is all too common to merit comment. But this case embodies several elements that illustrate some of the dilemmas described in the preceding section.

The child, who was not wearing a helmet, was hit by a car. At the time of writing, it has not been possible to confirm the details but, apparently, the driver was elderly and had previously struck a child; he was regarded in the neighbourhood as a dangerous driver. While that characterization may be disputed, his age is a matter of public record. So is the province's attitude towards the reexamination and licensing of elderly drivers.

The fact that the child was a resident of a municipality that is one of many that do not require helmets to be used by roller-bladers, skate-boarders, let alone bicyclists, is also noteworthy, and a matter of record.

And, finally, when the case was presented to the Trauma Committee of our hospital, there was a great deal of critical self examination and soul searching regarding the procedures following the child's arrival in the hospital. Was the team properly organized? Was the necessary equipment available? Was it just a matter of good luck that an anaesthetist happened to be at hand when a craniotomy was required? These, and many more questions, were raised with a view tof improving the care provided for the next such victim. (If onlyes the same attitude applied to the town council's position on helmets and that of the province on licensing!)

Typically, there was little time during the Traumad Committee's meeting to discuss the preventive issues, andके in the end the coordinator of the Head and Spinal Cord Trauma Program and I were left to agonize about what to do. Should we publicize this tragedy, with a view to drawing attention again to the need for helmet legislation, which 15 may have reduced the severity of the injury (secondary prevention)? Or, indeed, should we draw attention to the need for stricter regulation of older drivers, to say nothing of those regarded as dangerous (primary prevention)? 
But how to bring all this about? Normally, such tragedies are reported in the press, and a letter to the editor of various influential newspapers serves to call attention to the issues and may help. This is, of course, not enough. In this instance, there was no news coverage, and we were reluctant to contact the family to obtain more details about the driver, the primary cause of this tragedy. They were, no doubt, overwhelmed with guilt-some justified, per- haps - for the poor judgment shown in allowing a 6 year old to skate-board and to do so without a helmet. But, in fairness to the family, we, society, failed to make the need for these safety measures widely evident. And in particular, we failed to remove the dangerous driver from circulation. Furthermore, there is little likelihood that their guilt would have been assuaged by the police report; it is almost certain to have, in effect, 'blamed the victim' or his parents.

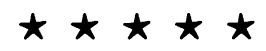

\section{New features in the journal}

In this issue we introduce two new features, one of which was previewed in an earlier issue. This is the Introduction to Statistics column written by Robert Platt in which he attempts to simplify points that, for many of us, including those who fancy themselves well trained researchers, often stumble over. But his main audience is intended to be nonresearch readers whose eyes glaze over when they read the words 'confidence interval' or 'analysis of variance'. Platt will do his best to keep it simple without compromising the accuracy of what is written. This, like so much else the balancing act this journal attempts, will be difficult. Please let him and me know how he is succeeding, and, if you have any favourite statistical mysteries that need to be unravelled, don't hesitate to ask.

The other new feature is an occasional column from a frequent contributor to PedNet (Pedestrian Network), one of the many listservers available through e-mail that include topics related to injury prevention. The writer, Peter Jacobsen, is an engineer in California. His comments attracted my attention and I asked him to highlight any 'threads' he believes will be of interest to our readers.

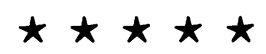

\section{Medical Editors Trial Amnesty}

META (Medical Editors Trial Amnesty) was initiated by the indomitable Ian Roberts, a hardworking member of our editorial board. It arises from his concern - a concern shared by many others - that there is a bias by editors, and perhaps by reviewers, against publishing trials with negative results. Thus, when attempts are made to systematically review the literature, especially using meta-analysis, these results are not available and the conclusions likely to be distorted. We have agreed, along with many other journals, to publish the appeal to researchers who have such unpublished trials, to submit the details (see p 233). I urge everyone to do so.

I B PLESS Editor 